\title{
Quality of Life and Subjective Burden on Family Caregiver of Children with Autism
}

\author{
Omaima Ezzat ${ }^{1}$, Magda Bayoumi ${ }^{2,}$, Osama A Samarkandi ${ }^{3}$ \\ ${ }^{1}$ Mental Health \& Psychiatric Nursing, Nursing Faculty, Beni-Suef University, Beni-Suef, Egypt \\ ${ }^{2}$ Medical Surgical Nursing, Nursing Faculty, Beni -Suef University, Beni-Suef, Egypt \\ ${ }^{3}$ Nursing Informatics, Prince Sultan College for Emergency Medical Services, King Saud University, Riyadh, KSA
}

\section{Email address}

mbayoumi@nursing.bsu.edu.eg (M. Bayoumi)

${ }^{*}$ Corresponding author

\section{To cite this article:}

Omaima Ezzat, Magda Bayoumi, Osama A Samarkandi. Quality of Life and Subjective Burden on Family Caregiver of Children with Autism. American Journal of Nursing Science. Vol. 6, No. 1, 2017, pp. 33-39. doi: 10.11648/j.ajns.20170601.15

Received: November 29, 2016; Accepted: December 8, 2016; Published: January 23, 2017

\begin{abstract}
Background: Caring for children with autism has been affected on caregivers' health outcome and cause high stress levels and health disturbance on family caregiver. Aim: the main aim of the present study was to assess the quality of life and subjective burden on family caregiver of children with autism. Methods: A quasi-experimental design was carried out in the primary and preparatory school in Beni-Suef City from November 2015 to January 2016. Data were obtained from a total of 86 caregivers, 36 caregivers as interventional group and 50 caregivers as control group were interviewed by using Zarit Burden Interview (ZBI) and QoL.SF 36-item. Results: All caregivers in the study and control group were female; they also had the same age. The findings reported a significant difference between caregivers of autistic and control groups in burden levels, and around half of autistic caregivers (47.2\%) have sever level. Moreover autistic caregivers reported significantly lower quality-of-life, compared with control group in physical functioning and energy/fatigue. Conclusion: caregivers of children with autism show higher levels of burden and lower level of QoL compared to control group. Thus further research is needed to identify coping strategies that can decrease overall burden on family caregiver.
\end{abstract}

Keywords: Quality of Life, Subjective Burden, Family Caregiver, Autism

\section{Introduction}

Autism is a lifelong developmental disorder recognized by significant impairment in social interaction, communication and the presence of restricted and repetitive behaviors or interests [1]. Recent study reported that autism is considering a challenge in social interaction and a heightened sensory perception [2]. Moreover, autism is a complex neurodevelopmental trouble which prevents the child from socio-communicative interaction and learning activity[3]. However, the literature reported the autistic disorder may be diagnostic since 60 years ago but its cause remains unknown [4].

Nowadays, significantly the number of children with autism increasing and is considering a stressful event for a family because of the correlative negative effects [5]. Surprisingly; the first study ever done on the cost consequences of Autism Spectrum Disorder (ASD) in Egypt reported, the currently estimated that 3 to 6 children out of every 1,000 worldwide have ASD [6]. Males are 4 times more likely to have ASD than females [7] furthermore; early intervention such using multidisciplinary educational and behavioral approaches (e.g., applied behavior analysis, skill oriented training therapies for social and language development), prescribed medication for specific symptoms, such as anxiety, depression, attention deficit disorder, customized sessions (physical and speech), and hyperactivity, obsessive compulsive behavior [6].

Unfortunately, caregivers of children with autism face numerous challenges and many studies reported increased psychological distress including depression [8-11]. However factors reported related to caregiver depression were children's behavior problems, early onset of autism, low functioning of patients, inadequate social support that 
caregivers received, caregivers suffering from co-morbid conditions or disability [12-13] Furthermore, factors relating to caregiver burden were severity of patient's symptoms, number of life problems of caregiver and low level of support that caregiver received [14]

Assessment of quality of life is very important indicator for well being and includes multidimensional aspects, according to world health organization (WHO) defines Quality of Life as individuals perception of their position in life in the context of the culture and value systems in which they live and in relation to their goals, expectations, standards and concerns [15]. However modify patients' life style will be improve quality of life and reduce burden on family caregivers [16]. In fact, burden on family caregivers concerning people with chronic diseases is described as a disorder resulting from patients' physical dependence and mental incapacity [17].

In order to understand and guide the caregiver for coping and improve their overall quality of life, the purpose of the present research was to assess the Quality of life and subjective burden among family caregivers of autistic children.

\section{Significance of the Study}

Numerous research studies have identified many problems associated with caring children with autism[18], these problems depend on many risk factors include gender of caregiver, amount of time spent caring for children, marital status, parental education and caregivers' Quality of life, therefore the behavior problems of autistic disorder $[19,22]$.

\section{Aim}

1. To assess the Quality of life among family caregivers of autistic children.

2. To evaluate the subjective burden among family caregivers of autistic children.

3. To correlate between Quality of life and Subjective burden among family caregivers of autistic children.

\section{Research Question}

Is there relationship between Quality of life and Subjective burden among family caregivers of autistic children?

\section{Subjects and Methods}

\subsection{Research Design and Setting}

A quasi-experimental design was used in carrying out this study in Beni - Suef City

\subsection{Subject Recruitment}

Caregivers of children diagnosed with autism were consecutively recruited in the special needs and merging primary and preparatory schools in Beni-Suef city. Autistic criteria were excluded in controls before entering the study.

\subsection{Tools for Data Collection}

\subsubsection{Caregivers' Demographic Data}

Age, sex, work status, level of education and financial status.

\subsubsection{Zarit Burden Interview}

Burden were assessed with Caregiver Burden Interview. This consisted of a 22-item self-report instrument; the Zarit Burden Interview (ZBI) was completed by caregivers as a measure of subjective response to caregiving. The dimensions of the subjective burden tool have been determined by Zarit [18-19], and translated tool in Arabic get from original author [20].

Scoring:

The burden interview is scored by summing the responses of the individual items. Higher scores indicate greater caregiver distress. The level of subjective burden was determined according to the following scoring: $(0$ - 20) little to no burden, (21 - 40) Mild to Moderate, (41 - 60) Moderate to severe burden and (61 - 88) Sever burden.

\subsubsection{Caregivers' Quality of Life (QoL)}

Medical Outcome Study "QoL.SF 36-item" health survey version 1.0 taps eight health concepts: physical functioning, bodily pain, role limitation due to physical health problem, role limitation due to personal or emotional problem, emotional well-being, social functioning, energy/fatigue, and general health perception [21].

Scoring:

Each item is scored on a $0-100$ range so that the lowest and highest possible scores are set 0 and 100 respectively. Scores represent the percentage of possible total score achieved. Then items in the same scale are averaged together to create each scale. High scores define a more favourable health state.

\subsection{Ethical Considerations}

The study protocol was approved by the ethical scientific research committee at the Faculty of Nursing, Beni-Suef University and ministry of education in Beni- suef. An informed consent was obtained from each participant before collecting any data explaining the study aim in a simple and clear manner to be understood by common people. No harmful maneuvers were performed or used, and no foreseen hazards were anticipated.

\subsection{Pilot Study}

The pilot study conducted on $10 \%$ of the total study sample to ensure the clarity and applicability of the tool and the time needed to complete them, no modifications were done. Caregivers participated in the pilot study were included in the total sample size, because of small sample size. 


\subsection{Operational Design}

\subsubsection{Field Work}

Personal interviews with the caregivers were scheduled at study settings. The researcher started to collect data daily from caregivers. A number of 3-5 caregivers were interviewed per day. The interview took from 10-15 minutes. The process of data collection took a period of three months, November 2015 to January 2016

\subsubsection{Administrative Design}

An official permission was obtained from the administrator of the schools after explaining the nature of the work. The researcher met with them and explained the aim and the process of the study. Caregivers' consents were obtained. Complete confidentiality of any obtained information was ensured. The researcher has also assured the administration that the conduction of the study will not affect the work in the study settings. The results of the study will be provided to the schools' authorities.

\subsection{Statistical Design}

Data entry and statistical analysis were done using SPSS 20.0 statistical software package. Qualitative categorical variables were compared using chi-square $t$ and means and standard deviations for quantitative variables. For statistical group comparisons of autistic care givers vs. controls, independent-sample $t$-tests and correlations were computed.

\section{Results}

Table 1 indicates a similarity of the socio-demographic characteristics of care givers in the study and control groups. All caregivers in the study and control group were female; they also had the same age. The majority of them were read and write and preparatory education, working and mothers of children. Moreover, none of these differences however were statistically significant.

Table 1. Socio-demographic and family characteristics of care givers in the study and control groups.

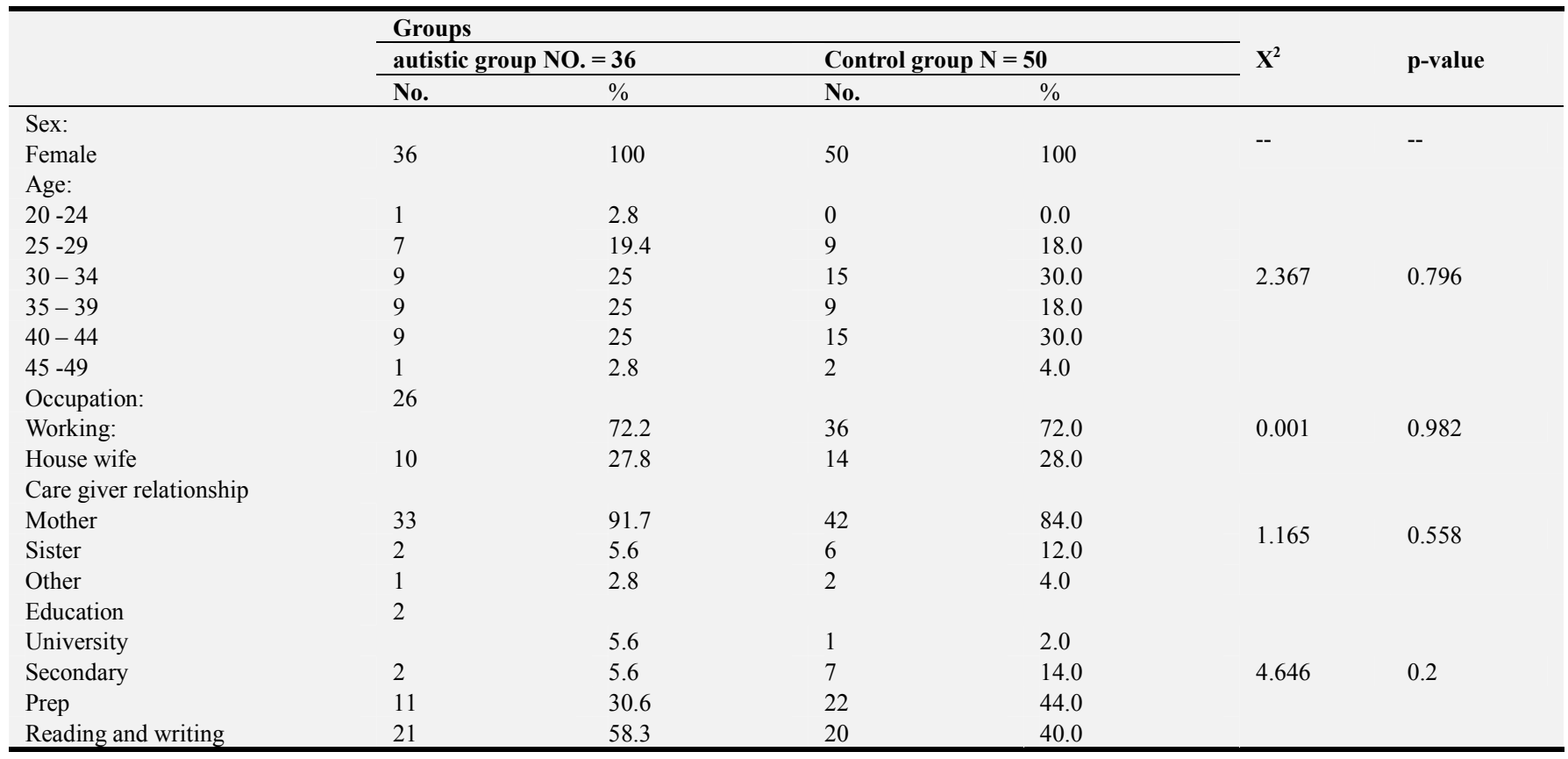

(*) Statistically significant at $\mathrm{p}<0.05$

(**) highly Statistical significant at $\mathrm{p}<0.01$

As regards, children Table 2; demonstrates no differences of statistical significance. Majority of children were male and aged between $(6-9)$ years. Also more than two third in primary education, none of these differences however were statistically significant.

Table 2. Socio-demographic characteristics of children in the study and control groups.

\begin{tabular}{|c|c|c|c|c|c|c|}
\hline & \multicolumn{4}{|c|}{ Groups } & \multirow{3}{*}{$\mathbf{X}^{2}$} & \multirow{3}{*}{ p-value } \\
\hline & \multicolumn{2}{|c|}{ Autistic group No.=36 } & \multicolumn{2}{|c|}{ Control group No. $=\mathbf{5 0}$} & & \\
\hline & No. & $\%$ & No. & $\%$ & & \\
\hline \multicolumn{7}{|l|}{ Age: } \\
\hline $6-9$ & 29 & 80.6 & 42 & 84.0 & \multirow{3}{*}{0.197} & \multirow{3}{*}{0.906} \\
\hline $10-12$ & 5 & 13.9 & 6 & 12.0 & & \\
\hline $13-15$ & 2 & 5.6 & 2 & 4.0 & & \\
\hline Sex: & & & & & \multirow{2}{*}{0.001} & \multirow{2}{*}{0.98} \\
\hline Male & 28 & 77.8 & 28 & 77.8 .0 & & \\
\hline
\end{tabular}




\begin{tabular}{|c|c|c|c|c|c|c|}
\hline & \multicolumn{4}{|c|}{ Groups } & \multirow{3}{*}{$\mathbf{X}^{2}$} & \multirow{3}{*}{ p-value } \\
\hline & \multicolumn{2}{|c|}{ Autistic group No.=36 } & \multicolumn{2}{|c|}{ Control group No. $=50$} & & \\
\hline & No. & $\%$ & No. & $\%$ & & \\
\hline $\begin{array}{l}\text { Female } \\
\text { Education: }\end{array}$ & 8 & 22.2 & 8 & 22.2 .0 & & \\
\hline PRIMARY & 23 & 63.9 & 39 & 78.0 & 2.072 & 0.223 \\
\hline Preparatory & 13 & 36.1 & 11 & 22.0 & & \\
\hline
\end{tabular}

(*) Statistically significant at $\mathrm{p}<0.05$

$(* *)$ highly Statistical significant at $\mathrm{p}<0.01$

Table 3 illustrates highly significant difference between caregivers of autistic and control groups in burden levels. Around half of autistic caregivers (47.2\%) have sever level, more than one third (36.1) have moderate to severe level and (0.0\%) have no to little level. However, around half of control group (48.0) have no to little burden and only (2.0\%) have sever burden.

Table 3. Level of psychological burden in autistic and control group.

\begin{tabular}{|c|c|c|c|c|c|c|}
\hline & \multicolumn{4}{|c|}{ Groups } & \multirow{3}{*}{$X^{2}$} & \multirow{3}{*}{ p-value } \\
\hline & \multicolumn{2}{|c|}{ Autistic group No. $=36$} & \multicolumn{2}{|c|}{ Control group No. $=\mathbf{5 0}$} & & \\
\hline & No. & $\%$ & No. & $\%$ & & \\
\hline No to little burden & 0 & 0 & 24 & 48 & \multirow{4}{*}{46.515} & \multirow{4}{*}{0.00} \\
\hline Mild to moderate level & 6 & 16.7 & 19 & 38 & & \\
\hline Moderate to sever & 13 & 36.1 & 6 & 12 & & \\
\hline Sever burden & 17 & 47.2 & 1 & 2 & & \\
\hline
\end{tabular}

(*) Statistically significant at $\mathrm{p}<0.05$

(**) highly Statistical significant at $\mathrm{p}<0.01$

Table 4 revealed autistic caregivers reported significantly lower quality-of-life, compared with control group in physical functioning and energy/fatigue. They also had highly significant decreased scores, indicating lower quality-of-life on domains of bodily pain, role limitation due to personal or emotional problem, emotional well-being, social relationship, general health perception, and total quality of life score. The only exception is role limitation due to physical health problem the difference was not statistically significant.

Table 4. Comparison of Quality-of-life in autistic care givers of autism and control groups.

\begin{tabular}{lllll}
\hline & \multirow{2}{*}{ T test } & \multicolumn{2}{l}{ Mean } & \multirow{2}{*}{ P value } \\
\cline { 3 - 5 } & & autistic group & Control group & 0.04 \\
physical functioning & 2.006 & 64.58 & 75.70 & 0.00 \\
bodily pain & 2.802 & 66.60 & 79.15 & 0.16 \\
role limitation due to physical health problem & 1.411 & 37.58 & 49.06 & 0.00 \\
role limitation due to personal or emotional problem & 2.995 & 27.86 & 54.06 & 0.000 \\
emotional well-being & 4.194 & 50.78 & 66.32 & 0.00 \\
social functioning & 3.220 & 53.82 & 69.00 & 0.05 \\
energy/fatigue & 1.931 & 44.03 & 50.40 & 0.00 \\
general health perception & 3.397 & 60.83 & 72.10 & 0.00 \\
Total scores of quality of life & 4.207 & 406.08 & 515.79 & \\
\hline
\end{tabular}

(*) Statistically significant at $\mathrm{p}<0.05$

$(* *)$ highly Statistical significant at $\mathrm{p}<0.01$

Table 5 indicates; comparison of burden of autistic and control group, as table shows; highly significant differences, indicating greater burden, in autistic group.

Table 5. Comparison of burden of autistic and control group.

\begin{tabular}{llll}
\hline & T test & Mean & Control group \\
\cline { 3 - 4 } & & Autistic group & 43.70 \\
\hline Psychological burden & 4.822 & 55.64 & 0.00 \\
\hline
\end{tabular}

${ }^{*}$ Statistically significant at $\mathrm{P}<0.05$

** highly statistically significant at $\mathrm{P}<0.01$

Table 6 demonstrates highly statistically significant negative correlations between various QoL domains' and burden. 
Table 6. Correlation between burden and quality of life (QoL) scores of autistic and control group.

\begin{tabular}{lll}
\hline & Psychological Burden & \\
\cline { 2 - 3 } & Pearson correlation & P value \\
\hline physical functioning & -0.433 & 0.00 \\
bodily pain & -0.570 & 0.00 \\
role limitation due to physical health problem & -0.514 & 0.00 \\
role limitation due to personal or emotional problem & -0.654 & 0.00 \\
emotional well-being & -0.805 & $-.894-$ \\
social functioning & -0.511 & 0.00 \\
energy/fatigue & -0.532 & 0.00 \\
general health perception & -0.459 & 0.00 \\
Total scores of quality of life & -0.894 & 0.00 \\
\hline
\end{tabular}

*Statistically significant at $P<0.05$,

** highly statistically significant at $P<0.01$

On multivariate analysis (Table 7), illustrates, highly significant independent negative predictors on the burden score were total score of quality of life in addition to emotional well-being. The model explained ( $86 \%)$ of the variation in the burden score as indicated by the r-square value of the model. The other quality of life domains had no independent effect on burden.

Table 7. Best fitting multiple linear regression model for psychological burden.

\begin{tabular}{|c|c|c|c|c|c|}
\hline & \multicolumn{2}{|c|}{ Unstandardized Coefficient } & \multirow{2}{*}{ Standardized coefficient } & \multirow{2}{*}{ t- test } & \multirow{2}{*}{ P-value } \\
\hline & B & Std. error & & & \\
\hline Constant & 91.221 & 2.643 & & 34.514 & 0.00 \\
\hline Emotional well-being & -0.229 & 0.073 & -0.344 & 3.132 & .000 \\
\hline Total & -0.059 & 0.010 & -0.628 & 5.712 & 0.00 \\
\hline
\end{tabular}

R-square $=0.860$; Model ANOVA: $\mathrm{F}=101.025, \mathrm{P}<0.00$ Variables excluded by model: physical functioning, bodily pain, role limitation due to physical health problem, role limitation due to personal or emotional problem, social functioning, energy/fatigue, general health perception.

\section{Discussion}

Caregiver research has been very important part to explore burden, stress and depression as outcomes of caregiving. There is little research assessing the burden and quality of caregivers, and some authors reported that changes in family structure related to increased participation of mother as employee, house wife and other responsibilities at family [22]

The results observed in this study made it possible to analyze level of burden for caregiver of children with autism and different aspects of caregivers' Qol. The foregoing present study finding concerning the demographic characteristics of the caregiver are in the agreement with Lerthattasilp et al, 2015 who have measured depression and burden among caregivers of children with autistic spectrum disorder [23].

In the agreement with the current finding regarding to level of burden on family caregiver, Mugno et al, 2007 reported most families with autistic child reported that they had a high burden level [24], other study by Ling Y et al, 2007 showed that 80 percent of mothers of children with autism had midrate to extremely sever level o caregiver burden [25].

As well as children with autism have many problems, and in turn the problems means that the caregivers have to simultaneously handling problems in more aspects and finally cause severe burden on caregiver [26].

Task assigned to caregiver, often without appropriate guidance and support from special institutions to family caregiver must be affect their quality of life (QoL) [27]. Thus, autistic caregivers reported in our study significantly lower quality-of-life, compared with control group in physical functioning and energy/fatigue, so the results agreed with recent study results done by Misquiatti et al 2016 [28].

Furthermore, caring for children with autism can be associated with decline in physical and mental tasking job and resulting in compromised (QoL) of carers [29]. In the agreement of our study findings the study by Hoefman et al, 2014 reported the correlation between QoL scores and subjective burden level and found the impact of QoL positively associated with higher subjective and lower caregivers" QoL [30].

Literature reported that caring for children with autism is challenging and affects family life related to diagnosis of restricted behavioral functions such as sterotype behavior or inability to adjust to new situation [31]. In addition improvement of caregivers' well being could be positively influence the effect on the intervention of those children [32].

\section{Conclusion}

This study highlighted very important issue may be neglected and focused on caregiver of children with autism in our sample described realization sever subjective burden from providing care for their child with an autism, this caregiving absolutely affect their own quality of life, as well as further research is needed. 


\section{Recommendation}

- Recognize coping strategies used by family caregiver for handling children with autism.

- Provide suitable ways to support family adaptation by institutions such as schools and insurance.

- Establish collaborative group as physicians, nursing staff and other professionals is very important to play important role with caregiver and pay more attention for those children and their family caregiver.

\section{References}

[1] American Psychiatric Association. Diagnostic and statistical manual of mental disorders. 4th ed. Text Revision (DSM-IVTR). Washington, DC: American Psychiatric Publishing; 2000.

[2] Rogers C, Lepherd L, Ganguly R, Jacob-Rogers S. Perinatal issues for women with high functioning autism spectrum disorder. Women Birth. 2016 Oct 14. pii: S18715192(16)30128-7.

[3] Geoffray MM, Thevenet M, Georgieff N. News in early intervention in autism. Psychiatr Danub. 2016 Sep; 28 (Suppl1): 66-70.

[4] Wolff S. The history of autism. Eur Child Adolesc Psychiatry. 2004 Aug; 13 (4): 2018.

[5] Charnsil C, Bathia M. prevalence of depressive disorders among caregivers of children with autism in Thailand. ASEAN Journal of Psychiatry, 2010 Vol. 11 (1) 1-9.

[6] Mendoza R. The Economics of Autism in Egypt. Am. J. of Economics and Business Administration 2 (1): 12-19, 2010.

[7] Fombonne, E., 2003. Epidemiological surveys of autism and other pervasive developmental disorders: An update. J. Autism Dev. Disorders, 33: 365-382.

[8] Higgins DJ, Bailey SR, Pearce JC. Factors associated with functioning style and coping strategies of families with a child with an autism spectrum disorder. Autism 2005; 9: 125-37.

[9] Sivberg B. Coping strategies and parental attitudes, a comparison of parents with children with autistic spectrum disorders and parents with non-autistic children. Int $\mathbf{J}$ Circumpolar Health 2002; 61 (Suppl 2): 36-50.

[10] Weiss MJ. Harrdiness and social support as predictors of stress in mothers of typical children, children with autism, and children with mental retardation. Autism 2002; 6: 115-30.

[11] Yirmiya N, Shaked M. Psychiatric disorders in parents of children with autism: a meta-analysis. J Child Psychol Psychiatry 2005; 46: 69-83.

[12] Tarabek J. Relationship satisfaction and mental health of parents of children with autism: acomparison of autism, ADHD, and normative children [thesis]. Blacksburg, VA: Faculty of the Virginia Polytechnic Institute and State University; 2011.

[13] Raina P, O’Donnell M, Schwellnus H, Rosenbaum P, King G, Brehaut $\mathrm{J}$, et al. Caregiving process and caregiver burden: conceptual models to guide research and practice. BMC Pediatr 2004; 4 : 1 .
[14] Stuart M, McGrew JH. Caregiver burden after receiving a diagnosis of an autism spectrum disorder. Res Autism Spectr Disord 2009; 3: 86-97.

[15] The World Health Organization Quality of Life assessment (WHOQOL): position paper from the World Health Organization. Soc Sci Med. 1995 Nov; 41 (10): 1403-9.

[16] Bayoumi M. life style modifications toward improving quality of life and reducing burden on faily caregiver: development of new nursing theory. Proceeding Scientific booklet, international conference of nursing science, Bioleagues, 1$3 / 11 / 2016$.

[17] Braithwaite V. Caregiving burden, making the concept scientifically useful and policy relevant. Research on Aging. 1992; 14 (1): 3-27.

[18] Zarit SH, Reever KE, Bach-Peterson J. Relatives of the Impaired Elderly: Correlates of Feelings of Burden. The Gerontologist. 1980; 20 (6): 649-55.

[19] ZBI 12 items: Bédard M, Molloy DW, Squire L, Dubois S, Lever JA, O'Donnell M. The Zarit Burden Interview: A new short version and screening version. The Gerontologist 2001; 41: 652-657.

[20] Bayoumi M. Subjective Burden on Family Carers of Hemodialysis Patients. Open Journal of Nephrology, 2014, 4, 79-85.

[21] Hays R. D \& Shapiro M. F. An Overview of genetic Health Related Quality of Life measures for HIV. Research, Quality of life research, 1992; 1: 91-97.

[22] Tessler RC, Gamache GM. Family experiences with mental illness. $1^{\text {st }}$ ed. Westport: Auburn House; 2000.

[23] Lerthattasilp T, Charernboon T, Chunsuwan I, Siriumpunkul P. Depression and Burden among Caregivers of Children with Autistic Spectrum Disorder. J Med Assoc Thai, 2015; Vol. 98 Suppl. 2: 45-52.

[24] Mugno D, Ruta L, D’Arrigo VG, Mazzone L. Impairment of quality of life in parents of children and adolescents with pervasive developmental disorder. Health Qual Life Outcomes 2007; 5: 22.

[25] Lin Y, Orsmond L G. Maternal well-being and lifespan issues of autism in Taiwanese families of adolescents and adults with autism spectrum disorders. The 18th Asian conference on mental retardation; 18-23 November 2007 Taipei, Taiwan; 2007: 618-28.

[26] Toonsiri C, Sunsern R, Lawand W. Developmental of the burden interview for caregivers of patients with chronic illness. J Nurs Educ 2011; 4: 62-75.

[27] Amendola F, Oliveira MAC, Alvarenga MRM. Qualidade de vida dos cuidadores de pacientes dependentes no programa de saúde da família. Texto Contexto Enferm. 2008; 17 (2): 26672.

[28] Misquiatti A, Brito M, Ferreira F, Junior F. Family Burden And Children With Autism Spectrum Disorders: Perspective Of Caregivers. Rev. CEFAC. 2015 Jan-Fev; 17 (1): 192-200.

[29] Ganjiwale D, Ganjiwale J, Sharma B, Mishra B. Quality of life and coping strategies of caregivers of children with physical and mental disabilities. J Family Med Prim Care. 2016 Apr-Jun; 5 (2): 343-348. 
[30] Hoefman R, Payakachat N, van Exel J, Kuhlthau K, Kovacs E, Pyne J, Tilford JM. Caring for a child with autism spectrum disorder and parents' quality of life: application of the CarerQol. J Autism Dev Disord. 2014 Aug; 44 (8): 1933-45.

[31] Strock, M. Autism spectrum disorders (pervasive developmental disorders). Bethesda: National Institute of Mental Health (NIMH); 2007.

[32] Giallo R, Wood CE, Jellett R, Porter R. Fatigue, wellbeing and parental self-efficacy in mothers of children with an autism spectrum disorder. Autism. 2013; 17: 465-480. 